\title{
SERUM TROPONIN T LEVEL AND ECG CHANGES IN ACUTE ISCHAEMIC STROKE
}

\author{
Philomena James ${ }^{1}$, Rangaswami Mangalasundaram², Lavanya Manickam³
}

${ }^{1}$ Associate Professor, Department of General Medicine, Government Vellore Medical College, Vellore, Tamilnadu.

${ }^{2}$ Assistant Professor, Department of General Medicine, Government Vellore Medical College, Vellore, Tamilnadu.

${ }^{3}$ Post Graduate, Department of General Medicine, Government Vellore Medical College, Vellore, Tamilnadu.

\section{ABSTRACT}

\section{BACKGROUND}

Serum troponin elevation, characteristic of ischaemic myocardial injury, has been observed in some Acute Ischaemic Stroke (AIS) patients. ${ }^{[1]}$ Its cause and significance are still controversial.[2,3] The purpose of this study is to find determinants of troponin elevation and its relationship with stroke severity and location and to assess the prevalence of ECG changes in acute ischaemic stroke.

\section{METHODS}

Subjects with a diagnosis of Acute Ischaemic Stroke (AIS) presenting to Government Vellore Medical College and Hospital, Adukkamparai, from August 2015 to December 2015 were enrolled. Serum troponin T level was measured on admission. Patients were divided into two groups, Group 1 (Elevated cTnT) and Group 2 (Normal cTnT). Twelve lead standard electrocardiogram (ECG) was performed and stroke severity was assessed based on National Institutes of Health Stroke Scale (NIHSS).

\section{RESULTS}

Serum cTnT level was elevated in 19.56\% (18/92) of patients. In Group 1 (Elevated cTnT) there were 18 patients and in Group 2 (Normal cTnT) there were 74 patients. It was observed that insular lobe involvement was more frequent in elevated cTnT group (6/18) (31\%) than in Group $2(10 / 74)(14 \%)(p<0.05)$. ECG ischaemic changes were seen in 17 patients, $18 \%$ of patients. Stroke severity was greater in elevated cTnT group.

\section{CONCLUSION}

Troponin $\mathrm{T}$ elevation was associated with severity of stroke, higher age of the patients, ECG changes and Insular lobe involvement. Troponin $\mathrm{T}$ in acute ischaemic stroke is a marker of severity of stroke.

\section{KEYWORDS}

Troponin, Stroke, Location, Electrocardiography, National Institutes of Health Stroke Scale.

HOW TO CITE THIS ARTICLE: James P, Mangalasundaram R, Manickam L. Serum troponin T level and ECG changes in acute ischaemic stroke. J. Evolution Med. Dent. Sci. 2016;5(23):1255-1257, DOI: 10.14260/jemds/2016/292

\section{INTRODUCTION}

Stroke is defined as the primary pathology of brain vascular system that temporarily or permanently affects brain functions as a result of ischaemia and haemorrhage. Due to increase in trend of mortality and morbidity rates, stroke has become the major community problem for whole world. ${ }^{[4]}$ In the last decade, much interest has been drawn to the importance of serum troponin in acute stroke. Previous studies have shown that Troponin T is elevated in $10-30 \%$ of acute stroke patients. ${ }^{[5-7]}$ Some researchers have found association between troponin level and location and size of infarction, severity of stroke [Measured by National Institutes of Health Stroke Scale (NIHSS)], ischaemic electrocardiogram (ECG) changes and increased mortality. ${ }^{[8-11]}$ The purpose of this study is to investigate the relationship between cardiac troponin $\mathrm{T}$ and ECG changes in acute ischaemic stroke, its severity and location.

\section{Financial or Other, Competing Interest: None.}

Submission 18-02-2016, Peer Review 03-03-2016,

Acceptance 05-03-2016, Published 21-03-2016.

Corresponding Author:

Philomena James,

\#14, JP Salai,

Thendral Nagar,

Sathuvachari,

Vellore-9.

E-mail: rangsrad@gmail.com

DOI: $10.14260 /$ jemds $/ 2016 / 292$
During the last decade, it has become evident that acute stroke in many cases is accompanied by a rise in the concentration of troponins in serum indicating concomitant coronary disease.[12,4]

\section{The Aims of the present study were}

(i) To assess the prevalence of ECG and troponin T (TnT) abnormalities in acute ischaemic stroke.

(ii) Investigate the relationship between cardiac troponin $\mathrm{T}$ and severity and location of a stroke.

\section{MATERIALS AND METHODS}

Subjects with a diagnosis of Acute Ischaemic Stroke (AIS) presenting to Government Vellore Medical College and Hospital, Adukkamparai, from August 2015 to December 2015 were enrolled. Stroke patients were diagnosed according to World Health Organization definition (Sudden neurological deficit that has a presumable vascular aetiology). Ischaemic stroke was confirmed by showing diffusion restriction on diffusion-weighted imaging Magnetic Resonance Imaging (MRI). Stroke severity was assessed based on NIHSS.

Ninety two patients who met the WHO criteria for stroke with MRI brain showing AIS were enrolled. Informed consent was obtained from patients or responsible family members as applicable. On recruitment to the study demographic data were collected. Serum troponin $\mathrm{T}$ was measured as part of routine laboratory testing on admission. 
Troponin levels were measured by Roche Cobas E411CLIA-Chemiluminescent immune assay and was considered abnormal if it was $\geq 14 \mathrm{ng} / \mathrm{L}$. The patients were divided into two groups: an elevated cTnT (Group 1) and a normal cTnT (Group 2). Twelve lead standard ECG was performed.

Statistical analysis was performed: categorical and continuous variables were compared by Chi-square test and Student's t-test respectively. Invariable and multivariate logistic regression was used for further analysis; $p$ value $<0.05$ was considered statistically significant.

\section{RESULTS}

Serum cTnT level was elevated in $19.56 \%$ (18/92) of patients. In Group 1 (Elevated cTnT) there were 18 patients and in Group 2 (Normal cTnT) there were 74 patients (Fig. 1).

It was observed that insular lobe involvement was more frequent in elevated cTnT group (6/18) (31\%) than in group $2(10 / 74)(14 \%) \quad(p<0.05)$ (Fig. 2). ECG ischaemic changes were seen in 17 patients, $18 \%$ of patients. Stroke severity was greater in elevated cTnT group.
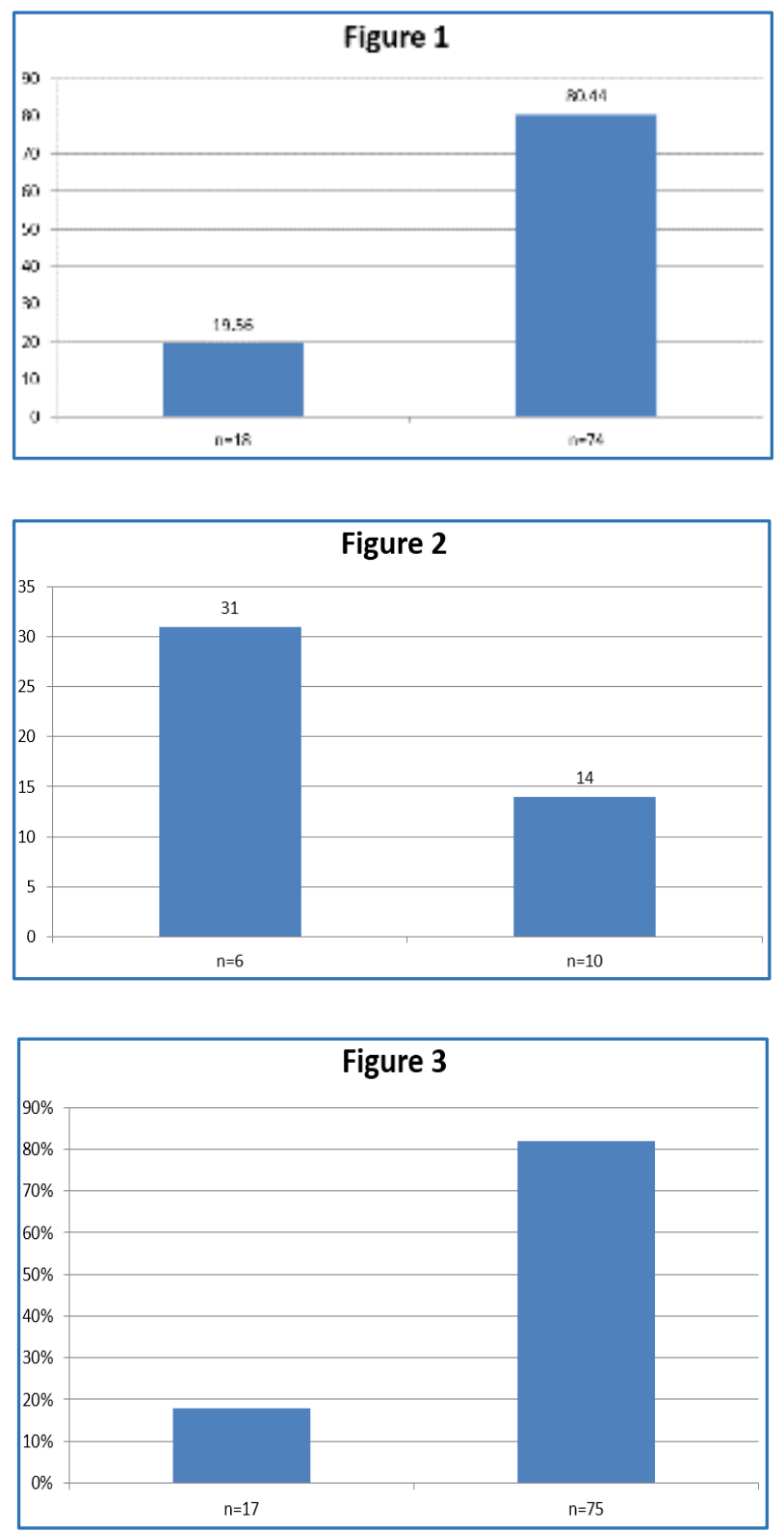

Table 1. Basic characteristics of enrolled Acute Ischaemic Stroke (AIS) patients.
Basic Characteristic Value

Age (Mean \pm SD) $67.58 \pm 14.98$

Male sex [n (\%)] 52 (57\%)

NIHSS [n (\%)]

$0-960(65.1)$

$10-1923(25.2)$

20-42 9 (9.7)

Abnormal serum creatinine $[\mathrm{n}(\%)] 9$ (7.9)

Serum troponin (ng/l).

Abnormal [n (\%)] 18 (19.56).

NIHSS: National Institutes of Health Stroke Scale.

Table 2. Electrocardiogram (ECG) changes of enrolled Acute Ischaemic Stroke (AIS) patients.

ECG changes n (\%)

ST depression $1(5.9 \%)$

$\mathrm{T}$ inversion 7 (41.1\%)

ST-T changes $4(23.5 \%)$

Atrial fibrillation 2 (11.8\%)

LBBB 2 (11.8\%)

RBBB 1 (5.9\%)

ECG: Electrocardiogram; LBBB: Left bundle branch block; RBBB: Right bundle branch block.

\section{DISCUSSION}

ECG abnormalities in the acute stage of ischaemic stroke were found in this study. The most frequent changes were T-wave inversion, ST-T wave changes. However, ischaemic ECG changes are known to be prevalent in elderly patients.[13,14] and accordingly as pre-stroke ECG records were not evaluated, pre-existing ECG changes cannot be differentiated from changes that occurred after onset of stroke symptoms.

Cardiac sequelae including myocytolysis, serum enzyme elevations and arrhythmias are known to develop in a portion of stroke patients. There is a great deal of clinical and experimental evidence that cardiac changes in stroke result from excessive sympathetic nervous activity secondary to insular cortical damage. It has been hypothesized that damage to centers regulating autonomic function can cause autonomic dysregulation resulting in sympathetic overflow and neurogenic myocardial injury.[15] Therefore, insula and brainstem were center of attention of many researchers.[16]

Some studies have shown that troponin level is higher in the right insular, brainstem or middle cerebral artery territory infarction.[17]

Insular lobe was predominantly involved in patients with elevated cTnT with possibility of neuro-myocardial injury. Stroke severity was found to be high in patients with elevated cTnT.

\section{CONCLUSION}

Troponin T elevations was associated with severity of stroke, higher age of the patients, ECG changes and Insula involvement. Troponin $\mathrm{T}$ in acute ischaemic stroke is a marker of severity of stroke.

\section{REFERENCES}

1. Abdi S, Oveis Gharan S, Sinaei F, et al. Elevated troponin $\mathrm{T}$ after acute ischaemic stroke: association with severity and location of infarction. Iran J Neurol 2015;14(1):3540. 
2. Kelley WE, Januzzi JL, Christenson RH. Increases of cardiac troponin in conditions other than acute coronary syndrome and heart failure. Clin Chem 2009;55(12):2098-112.

3. Jeremias A, Gibson CM. Narrative review: alternative causes for elevated cardiac troponin levels when acute coronary syndromes are excluded. Ann Intern Med 2005;142(9):786-91.

4. James P, Ellis CJ, Whitlock RM, et al. Relation between troponin $\mathrm{T}$ concentration and mortality in patients presenting with an acute stroke: observational study. BMJ 2000;320:1502-4.

5. Jensen JK, Kristensen SR, Bak S, et al. Frequency and significance of troponin $\mathrm{T}$ elevation in acute ischaemic stroke. Am J Cardiol 2007;99(1):108-12.

6. Ghali J, Allison D, Kleinig T, et al. Elevated serum concentrations of troponin $\mathrm{T}$ in acute stroke: what do they mean? J Clin Neurosci 2010;17(1):69-73.

7. Apak I, Iltumur K, Tamam Y, et al. Serum cardiac troponin $\mathrm{T}$ levels as an indicator of myocardial injury in ischaemic and hemorrhagic stroke patients. Tohoku J Exp Med 2005;205(2):93-101.

8. Wira CR, Rivers E, Martinez-Capolino C, et al. Cardiac complications in acute ischaemic stroke. West J Emerg Med 2011;12(4):414-20.

9. Song HS, Back JH, Jin DK, et al. Cardiac troponin T elevation after stroke: relationships between elevated serum troponin $\mathrm{T}$, stroke location, and prognosis. J Clin Neurol 2008;4(2):75-83.
10. Darki A, Schneck MJ, Agrawal A, et al. Correlation of elevated troponin and echocardiography in acute ischaemic stroke. J Stroke Cerebrovasc Dis 2013;22(7):959-61.

11. Balaney B, Batal O, Kolia N, et al. Troponin I elevation in acute ischaemic stroke. J Am Coll Cardiol 2013;61(10_S).

12. Trooyen $M$, Indredavik $B$, Rossvoll $\mathrm{O}$, et al. Myokardskade ved akutte hjerneslag bedomt med troponin I. Tidsskr Nor Laegeforen 2001;121:421-5.

13. Molaschi M, Ponzetto M, Romin R, et al. Changes in the electrocardiogram in the elderly patient. The limits between normality and pathology. Recenti Prog Med 1995;86:32-6.

14. Ahto $M$, Isoaho $R$, Puolijoki $H$, et al. Prevalence of coronary heart disease, associated manifestations and electrocardiographic findings in elderly finns. Age Ageing 1998;27:729-37.

15. Zeppellini R, Salsa F, Gheno G, et al. Cardiac injury in acute cerebral vasculopathy. Ann Ital Med Int 2001;16(2):73-81.

16. Colivicchi F, Bassi A, Santini M, et al. Cardiac autonomic derangement and arrhythmias in rightsided stroke with insular involvement. Stroke 2004;35(9):2094-8.

17. Ay $\mathrm{H}$, Koroshetz WJ, Benner $\mathrm{T}$, et al. Neuroanatomic correlates of stroke-related myocardial injury. Neurology 2006;66(9):1325-9. 